\title{
Cluster of design objects images in aesthetic and social, economic, and technological systems
}

\author{
Vladislav Zhukov ${ }^{1, *}$, Anastasia Smirnova ${ }^{1}$, Alina Vorobyova $^{1}$, and Ksenia Kosyakova ${ }^{1}$ \\ ${ }^{1}$ Saint Petersburg State University of Industrial Technologies and Design, Saint Petersburg, Russia
}

\begin{abstract}
Currently, there is no holistic concept of the creative possibilities of humanity and its civilizations, which confirms the relevance of this study. To create images of design objects - edged weapons, represented by visual-symbolic cognitive information dynamic systems (VKIDS) with locally stable structures (LUS) in the development of cognitive technologies of plastic arts and design, the methods of linguisticcombinatorial and tabular modelling were used. RESULTS: the morphogenesis of images of objects of design, represented by a cluster of bladed weapons and logotypes decor and marks of identification, as a result of cognitive technologies in the creation of SKIDS that provides a universal language of communication in relationships ontological and semiotic realities, which increases the growing importance of the plastic arts and design, focused on images of artefacts vintage and modern bladed weapons through the concepts of archetypes symbols and signs: system, taxonomy and classification.
\end{abstract}

\section{Introduction}

The development of weapons and their functions, like any other tool, is closely related to the global history of society, its economy, and the use of the forces of nature at this stage of development. As a living monument of history, the weapon preserves the stages of development and improvement of human thought in its quest to get the most effective solution to the problems that arise. The weapon reflects the level of knowledge and technology development of its time and is always at the highest point of human achievements, embodying all the most advanced ideas and technical solutions.

The attention of this study is drawn to the decorative properties of weapons, and above all this applies to edged weapons, which, without losing their main applied operational properties, creates trends:

- in accessories of jewellery and semiotic value, both traditional content and author's content;

- in symbolic and symbolic systems that reflect the social and technological mentality of design objects.

\footnotetext{
* Corresponding author: 1t_zhukova@mail.ru
} 
The systematic study of the images of the author's weapons and their semiotic nature of decoration is relevant from the point of view of a more precise definition of their typology, taxonomy, and classification in the plastic arts, industry, and design.

Currently, the design of jewellery and accessories takes place in the era of supernova technologies based on the principles of futurology and NBICS - convergence, which undoubtedly determine the main ways of developing modern design, especially cognitive technologies in creating images. However, the evolutionary and cyclical experience of the design theory of past periods does not allow us to forget certain stages of the formation and transmission of information reflected by the decor on the design objects with edict texts and symbolic and iconic logos, with the possible implementation of elements of jewellery art that formally encode the mental properties of material systems of complex cyber-physical space [1].

The creation of the author of the image of the object of design, including bladed weapons, in the theory of design, is always determined by the balance between item characteristics and communication morphology, of colour, of Eidos and concept defined cultural code entities, functional and decorative properties, and relations presents KIDS with locally-stable structure (LUZ) in semiotic reality through proportional mapping service appointment with a decorative solution.

The relevance of this scientific topic is determined by the ever-increasing aesthetic, cultural and social demand of society, which requires new research in cognitive technologies, in design theory, to understand the cultural code, which constantly increases the growing importance of plastic art and design, focused on the images of artefacts of rare and modern edged weapons through the concepts of archetypes of symbols and signs: system, taxonomy, and classification.

\section{Materials and methods}

In the course of the study, the analysis and synthesis of images of VKIDS with LUS in the application of cognitive technologies regarding edged weapons produced in Germany, Russia, Spain, and Sweden were carried out. The image of a modern-edged weapon - the dirk "Admirals of Russia" was created on the basis of a post-non-classical methodology.

\section{Results}

One of the important characteristics of images, which should be constantly in attendance, is the emergence of a new phenomenon, fundamentally different from other systems of images adopted for a certain field of knowledge, it is a sign that there is another, not yet explored side of objective reality. This shows the presence of the classification stage in the considered scientific picture of the world, through the theory of design, with its subject area of design objects represented by the VKIDS with LUS.

The results obtained systematize the taxonomy of images in the following directions:

images of natural origin are designated as the index;

- projects of cognitive technologies are divided into two categories-icons and symbols that show the achievement of the maximum rating of preference in the consumption of the product of their activity by society. Organizations, companies, and enterprises there is a need to identify the nomenclature code represented by the scales of the names or symbols of industry technological process in the national economy through design solutions, about how KIDS informing through the content of the text, font, and logo - a special mark of conformity with iconic properties that distinguish the product of the activities of the organization. This conformity mark is registered as a trademark or representative symbol of 
an enterprise, organization, or institution in accordance with the existing legislation of the Russian Federation according to on Technical Regulation: Federal Law No. 184-FZ of 27.12.2002.

Before the full assessment of such iconic images in a particular branch of knowledge and their classification into separate sciences - a time distance of enormous size. Indexes, icons, and symbols are semi-finished taxa that will undergo bifurcation into new iconic images of design objects of the author's compositional content and, in each case, with a scientific systematic approach to the existing ontological and semiotic reality. This is a very general plan for the specific application of taxa in the subject area of design objects, giving only the most global directions for the emergence of further specific and clear clusters of iconic images in design theory [2].

To create a symbolic system of images of the VKIDS, at least four essential conditions must be met:

- a set of homogeneous properties of symbolic images that encode related objects of research within the framework of this science, that is, design theory, in which cognitive technologies act in accordance with the fundamental laws of nature and design theory;

- a set of basic syntactic constructions of images that create an information field for the study of this science-the theory of design;

- a set of syntactic signs and links that control the LUS of the VKIDS within the selected information field;

- the presence of rules (algorithms), according to which the images are processed VKIDS are collected in the provisions of the theory of design.

Taxonomy units are taxa that include already discovered and potential (as yet unknown) classes of objects under study.

The classification includes groups of real and related objects and phenomena, which are depicted by the same symbolic images. These iconic images are devoid of their former logical content; their task is not to build different groups of objects and compare them with each other according to the degree of generality. Their task is to encode various objects with the same characteristic properties that can fit in a single cluster. The similarity of iconic images in the nature of the image and in the degree of their abstraction is a sign that the research has found real and homogeneous clusters of properties of design objects that fit into a single classification cell.

Cyclical nature is an important characteristic of iconic images. When a new and fundamentally different VKIDS is created, which is accepted in design theory and/or other fields of knowledge, it is a signal that there is a new, not yet explored side of objective reality. This leads to the conclusion that the research has reached the stage of classification in the considered scientific system-the theory of design.

This approach to encoding information with symbolic and text decor applied to edged weapons means that the requirements are met:

- the most accurate in stylistic and production-technological communication navigation state of the project with a conative function [3] in the modern design industry;

- providing technical and economic indicators of quality;

- axiological and adieska aspect is constantly in demand.

Morphology, colourists, eidos, and the concept of images of traditional and author's weapons are united in the artistic composition, so the beauty of weapons and their technical characteristics serve as an internal vector focused on their integrative qualities, defined by harmony, service purpose, life cycle and conative function in the field of operation, which can be traced through logos and other symbolic and sign systems of conformity-brands, markings (Table 1). They themselves, as an object of design, do not create an impersonal image hidden behind the brand of the company or the place of use but implement the identity of the author's work. 
It is characteristic that the author's project of the image is initially a research work in the manufacture of the design object.

At the same time, the studied images of archetypes of weapons are monuments of global history, plastic arts, and design, which store information about the influence of cognitive technologies on the improvement of human thought and its desire to get the most optimal and effective solution to aesthetic problems. Weapons, on the example of the USSR and the Russian Federation, reflect the level of culture and technology of their time [4], which can be traced through the systematization and typology of its cultural code and a special, special language of symbols and signs.

Table 1. National symbolic and symbolic images on cold weapons.

\begin{tabular}{|c|c|c|c|c|}
\hline No & Country, City & Note & Brand & Image \\
\hline 1 & $\begin{array}{l}\text { Germany, } \\
\text { Solingen }\end{array}$ & $\begin{array}{l}\text { The company Kuno Ritter } \\
\text { was founded in 1932, and } \\
\text { still exists under the name } \\
\text { "Hubertus" } \\
\text { Brand after } 1933 \text {. }\end{array}$ & $\begin{array}{l}\text { Kuno Ritter KR } \\
\text { Solingen inscribed in an } \\
\text { ellipse }\end{array}$ & $\left\{\begin{array}{l}\frac{\pi}{0} \\
\vdots \\
\frac{1}{2}\end{array}\right.$ \\
\hline 2 & Russia, Izhevsk & $\begin{array}{l}\text { From the second quarter of } \\
\text { the XIX century to } 1917 \text {. It } \\
\text { was placed on the heel of the } \\
\text { blade, at the bayonets - on } \\
\text { the neck }\end{array}$ & $\begin{array}{l}\text { Image Description-Bow } \\
\text { and arrow }\end{array}$ & \\
\hline 3 & Russia, Zlatoust & $\begin{array}{l}\text { Zlatoust factory (from the } \\
1870 \text { s to the beginning of the } \\
\text { XX century). It was applied } \\
\text { on the heel as a decoration }\end{array}$ & $\begin{array}{l}\text { Chrysostom } 1883 \mathrm{Op} \text {. } \\
\text { factory }\end{array}$ & \\
\hline \multirow[t]{2}{*}{4} & Spain & $\begin{array}{l}\text { Company: Fabrica de Armas } \\
\text { Production period: } 1953 \\
\text { Designation of origin of } \\
\text { weapons }\end{array}$ & $\begin{array}{l}\text { Fabrica de Armas La } \\
\text { coruna } 1953\end{array}$ & 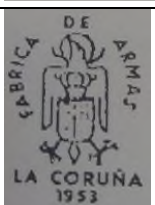 \\
\hline & $\begin{array}{l}\text { Sweden, } \\
\text { Huskvarna }\end{array}$ & $\begin{array}{l}\text { Designation of origin of } \\
\text { weapons }\end{array}$ & $\begin{array}{l}\text { Image of the crown, } \\
\text { abbreviations, and the } \\
\text { inscription " Sweden" }\end{array}$ & SWEOEN \\
\hline
\end{tabular}

The methods of linguistic-combinatorial [5-6] and tabular modelling [7] were used to develop the image of a commemorative ceremonial edged weapon (dirk). The dirk became the optimal type of weapon for mandatory use, as an element of the uniform of the command and commanding staff of the USSR Armed Forces. Since 1958, the daggers were part of the dress uniform of officers, and currently in the armed forces cutlass is an accessory dress general, officers, and warrant officers of all the armed forces, while retaining the basic design parameters of the samples with 1940-1943 years [8].

In this project, the archetypes of the images of cutlasses corresponding to the parameters of the admiral, general, and officer are used. The general's dirk, as a basic model, has a length with a scabbard $-460 \mathrm{~mm}$, and without a scabbard $-440 \mathrm{~mm}$, the blade is straight, flat, 
rhombic, double-edged, has a length of $330 \mathrm{~mm}$, a width of $17 \mathrm{~mm}$, (Fig. 1) and a guard in the representation of the symbol "Wind Rose" (Fig. 2) [9-10].
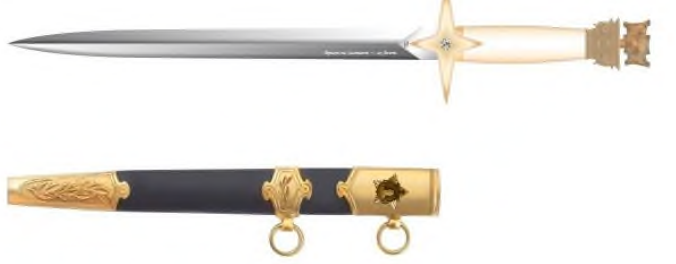

Fig. 1. Dirk «Admirals of Russia».

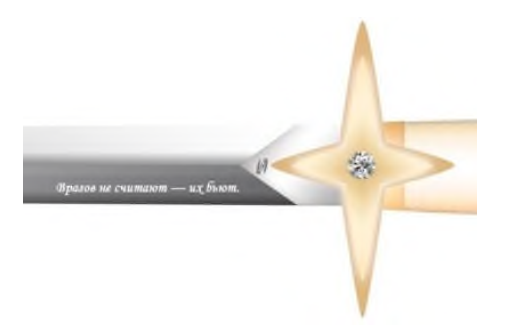

Fig. 2. Guard «Wind Rose».

\section{Discussion}

The weapon is part of the best of human thought. A modern person should have an idea of this part of social culture.

The author's edged weapons have great opportunities in the hybridization of various types of decorative art and technologies. This is the semiotic reality that determines the design and technological design of the dirk "Admirals of Russia", the choice of raw materials for its manufacture, taking into account the ergonomic properties of the product and the user.

\section{Conclusions}

Decorative finishing of weapons and their technology requires a high organization and culture of industrial production. Modern projects use engraving and printing techniques, which are most often used in the technique of multi-level etching and laser coloristic oxidation on metal. As a result of the conducted research, it should be concluded that it is necessary to further develop the theoretical basis for creating artistic images of cold weapons, as a semiotic direction of decorative and applied art and design.

\section{Acknowledgements}

The study was performed with the financial support of RFBR, research project No. 20-312-90056 (the reported study was funded by RFBR, project № 20-312-90056).

\section{References}

1. M. B. Ignatiev, Cybernetic picture of world (Saint Petersburg, GUAP, 2014)

2. A. B. Solomonik Semiotics and theory of knowledge. (Moscow, LIBROCOM, 2018) 
3. M. Bronwen, Ringham Felicitas Dictionary of Semiotics (Moscow, LIBROCOM, 2010)

4. V. N. Popenko Cold weapons of the East and We. (Moscow, 2018)

5. L. Zhukov, A. Smirnova, Lingvo-combinatorial method based on the fairy-tale creativity of A. S. Pushkin (Saint Petersburg, SPbGUPTD, 2017)

6. A. N. Rybakov, Kortik (Moscow, 2018)

7. M. S. Mirzoev Fundamentals of mathematical information processing (Moscow, Prometey, 2018)

8. E. A. Ostanina, Knives of the world: Fighting, collectible, hunting (Moscow, RIPOLL, 2004)

9. V. L. Zhukov, K. O. Gavrilova, E. V. Petrova, M\&T 4, 44 (2016) 